\title{
A Administração Pública e os Problemas da Automação
}

\author{
Araújo Cavalcanti
}

$35: 531.8$.

Condições e Perspectivas do Emprêgo da Automação nos Serviços Públicos

1. BREVE INTRODUÇÃO

\section{A - O Instituto Internacional de Ciências Administrativas e os Problemas da Automação}

Instituto Internacional de Ciências Administrativas já havia inscrito. no Programa de sua Mesa Redonda de 1957 - levada a efeito em Opatija, na Iugoslávia, - o estudo dêste fenômeno novo que constitui a automação na administração pública. A iniciativa do Instituto Internacional tinha como. objetivo contribuir para o progresso das ciências e das práticas administrativas. Considerado então sob um ângulo teórico, o estudo evoluiu, êste ano, para uma perspectiva mais prática dos problemas da automação, em função do desenvolvimento generalizado que os mesmos sofreram em quase. tôdas as regiões do mundo. Em Opatija, os problemas da automação foram objeto de considerações predominantemente doutrinárias; a Mesa Redonda de Liège - 27 de junho a 3 de julho de 1958 - revelou uma tendência diametralmente oposta.

O Instituto Internacional de Ciências Administrativas, pretendendo realizar um exame mais prático dos problemas da automação no âmbito da aḋministração pública, fêz elaborar e expedir prèviamente, um questionário detalhado cujos diferentes pontos podiam fàcilmente ser tratados pelas pessoas encarregadas da «mise-en-oeuvre» dos programas de automação.

Diversos países responderam a êste questionário e alguns dentre êles. julgaram mesmo útil acrescentar estudos complementares versando sôbre detalhes técnicos de instalação e de funcionamento dos conjuntos eletrônicos, bem como indicações relativas à adaptação técnica e intelectual do pessoal a serviço da automação.

$\mathrm{Na}$ parte final do presente trabalho encontram-se algumas informações baseadas na documentação proporcionada pela Mesa Redonda de Liège, acêrca das realizações, - tanto as que apresentam resultados concretos, como as que ainda se encontram na fase de projetos.

A finalidade primordial das pesquisas do Instituto - que terão prosseguimento de uma maneira continua no futuro, - é de saber qual é a situação. 
atual da automação na administração pública, quais são os domínios da atividade desta última susceptiveis de automação, assim como, estudar os problemas levantados pela implantação desta nova técnica e seus efeitos sôbre a rrganização, o pessoal e o rendimento dos serviços públicos.

A orientação básica do Instituto é no sentido de incluir no campo de suas pesquisas e estudos, apenas as aplicações da automação aos trabalhos administrativos realizados no seio da administração e das emprêsas públicas, excluindo, dessarte, o exame das operações industriais que poderiam efetuar eletrônica. mente estas últimas.

\section{$B-$ Terminologia}

A exatidão terminológica se tem revelado problema da maior importância no estudo da matéria e, desde o comêço das pesquisas, o Instituto se esforçou no sentido de proporcionar uma definição exata do têrmo «automação». Era preciso, com efeito, evitar as dificuldades que poderiam nascer de uma confusão entre vocábulos e conceitos tão diversos como «mecanização» e «automação», por exemplo.

Automation - a manufacturing system in which many or all of the processes are automatically performed or controlled, as by eletronic devices.

Automaton - 1) anything that can move or act of itself. 2) a person acting in a mechanical way (Webster's New World Dictionary of the American Language).

Esta preocupação se refletia, de resto, nos vários relatórios encaminhados ao Instituto, notadamente nos de Israel, da Itália e da França. Cronològicamente distinguem-se as seguintes etapas na organização do trabalho humano:

- trabalho manual.

- mecanização,

- ciclo completo de operações,

— automação.

A definição proposta pelo Relatório francês corresponde à concepção da automação tal qual foi desenvolvida pelo Instituto:

«Um ciclo completo de operações realizadas a partir de dados de base, sem classificação preliminar e sem intervenção humana manual ou intelectual, - no curso do «processus» com a possibilidade de obter ou de tratar uma informação elementar no curso dêsse ciclo».

Resulta dai que um simples trabalho na base de cartões perfurados não pode ser qualificado como «automação».

A automação permitirá pois resolver um certo número de problemas cuja natureza será definida posteriormente, - sem que se possa esperar, contudo, que a máquina seja capaz de, sòzinha, equacionar ou avaliar êstes problemas. Esta tarefa cabe ao homem que permanece, de qualquer forma, 
incumbido de duas fases extremamente importantes do trabalho eletrônico: a análise, de uma parte; e a programação, de outra: - isto é, a transcrição, na linguagem das máquinas, do conjunto das operações a efetuar.

\section{OBSERVAÇÕES GERAIS}

Embora já se possa afirmar que são bastante numerosas as aplicações da automação nas administrações públicas, é preciso acentuar que, na maior parte dos casos, esta automação encontra-se ainda no estágio dos estudos preliminares.

De fato, ainda é demasiado cedo para se extrairem conclusões em condições de servirem como princípios válidos ( «de principes valables») para todos os países e para os domínios nos quais a automação dos trabalhos administrativo é exeqüivel. A experiência demonstra ser cada aplicação um problema mais ou menos peculiar, cuja solução - ou a análise - é condicionada por uma grande variedade de elementos técnicos, práticos ou administrativos, muitas vêzes específicos.

À guisa de esclarecimento, indicaremos uma série de observações de alcance geral que resumem a substância, as condições e perspectivas da automação, nos limites obrigatòriamente resumidos e condensados destas ligeiras notas.

\section{A - A Automação Administrativa é um Fato Concreto}

As realizações concretas permanecem parciais; mas os estudos em andamento mostram que a automação parece rica de perspectivas não apenas nos numerosos dominios onde, até agora, sòmente a mecanização foi introduzida como, também, naqueles zampos em que a mecanização parecia impossivel, demasiado pesada ou muito lenta.

Não é necessário ligar obrigatòriamente a automação a uma mecanização preliminar se bem que, nesta eventualidade, os problemas de implantação sejam sensivelmente simplificados A automação oferece, por consequiência, possibilidades novas anteriormente inacessiveis.

Torna-se evidente que um alto grau de automação não pode ser atingido quando a execução de uma tarefa administrativa requer, freqüentemente, a intervenção de um julgamento.

Resulta daí que existem amplos setores dos serviços públicos nos quais a automação não é realizável. A automação, ao contrário, parece predestinada à aplicação, sobretudo naquelas tarefas ou encargos cuja execução requer numerosos registros, transmissão de dados, contabilizações, estatísticas, conservação e triagem de informações, cálculos, «ordonnancements», etc...

Encontram-se especialmente nêste caso as operações relativas aos pagamentos de salários e pensões, seguro social, operações de contas diversas, movimentação de correspondência, tributação, cadastros, administração de pessoal, documentação, serviços de telégrafos e telefones, inventários, fornecimentos, traduções, etc...

Dêste ponto de partida relativamente modesto, as experiências autorizam admitir-se e augurar o desenvolvimento ulterior de uma técnica que 
parece corresponder a uma necessidade das administrações modernas: o imperativo de se libertarem, até uma certa medida, das dificuldades que decorrem para elas do contínuo crescimento de suas tarefas, responsabilidades e encargos.

Essa possibilidade de adaptação a novas necessidades, corresponde, com efeito, a uma relativa transformação das exigências da ação administrativa, cada vez mais ligada à utilização de dados numéricos e práticos, de documentação ou de informações diversas, notadamente o crescente uso das estatisticas.

A conjuntura favorável de uma técnica em plena expansão e a ocorrência de necessidades novas não devem, porém, conduzir o técnico ou o adminis trador à convicção simplista de que a automação, pela sua natureza, resolverá todos os problemas ou facilitará a execução de certas tarefas administrativas sem que seja indispensável apreciar cuidadosamente - em cada caso de aplicação eventual, - suas possibilidades reais, efetivas, não sòmente no plano técnico, mas também tendo-se em conta o caráter específico da administração pública com suas peculiaridades. Em se tratando de automação, todo projeto de implantação requer uma grande prudência e implica estudos preliminares sistemáticos. A finalidade dêstes não é necessária e exclusivamente técnica; tais estudos podem esclarecer e determinar a necessidade de certas reformas de organização; dêles podem resultar simplificações quer práticas, quer legislativas, quer regulamentares.

Esta restrição não constitui de maneira nenhuma um empecilho à expansão e desenvolvimento da automação administrativa; muito pelo contrário ela representa umia garantia indispensável de seu sucesso, do êxito de sua implantação bem como de sua futura generalização em bases mais concretas.

\section{B - Os Problemas da Automação nos Serviços Públicos São Especificos}

O caráter específico, a natureza singular e as peculiaridades do emprêgo da automação nos serviços públicos repousam sôbre dois elementos:

a) a ocorrência de regras legais e regulamentares que condicionam a execução de certas tarefas administrativas susceptiveis de serem automatizadas e a influência das práticas administrativas tradicionais. Não se acentuaria demasiado esta subordinação - que não existe no setor privado, e à qual escapa, aliás, uma parte relativamente grande e importante das operações que, na administração pública, são semelhantes àquelas que se apresentam nas emprêsas privadas e organizações particulares... (cálculos, liquidação de pagamentos, salários, pensões, manutenção de contas correntes, cadastros, inventários, etc...) ou que escapam por sua natureza, a tôda regulamentação rigida;

b) a natureza especial de certos trabalhos administrativos, - desconhecidos no Setor privado, - e que necessitam uma adaptação particular das máquinas eletrônicas a serem utilizadas, senão a criação de novos conjuntos especificamente elaborados. Com efeito, certos trabalhos administrativos não fazem, senão subsidiàriamente, apêlo às possibilidades de cálculo das máquinas. Exige-se, sobretudo, neste caso, uma facilidade de acesso à memória aliada a uma grande capacidade de classificação e de «listing», e secundàriamente, de cálculo simples. Qualidades que os equipamentos atuais 
mais comumente empregados geralmente não apresentam em um grau satisfatório.

Pode-se deduzir, do confronto das respostas recebidas pelo Instituto, a existência de uma distinção fundamental no seio das operações susceptiveis de automação:

a) as operaçôes que se pode qualificar como tendo um dado fixo e um processo de execução pràticamente imutável (execução sucessiva de certas operações, em função de um objetivo determinado numèricamente, o ciclo sendo simplificado e normalmente redutivel. As aplicações menos complexas de automação);

b) as operações que não apresentam estas caracteristicas e que, por isso mesmo, requerem um estudo mais sistemático ultrapassando o plano técnico pròpriamente dito, para abordar diretamente problemas mais vastos em suas respectivas incidências. Esta situação apresenta duas ordens de consequiências que é preciso pôr em relêvo:

I - a necessidade de não limitar os estudos preliminares, indispensáveis a tôda automação, exclusivamente aos dados técnicos e de melhoramento dos métodos de trabalho. É assim que surgem desejáveis reformas que, por sua amplitude, ou suas conseqüências, não podem ser decididas senão em um escalão superior, de nivel mais alto, implicando mesmo uma colaboração do Legislador quando as reformas de estrutura tangenciam a legislação;

II - a obrigação de pesquisar, por vêzes, soluções novas, que não se apresentam, evidentemente, de uma maneira uniforme. A busca de soluções novas é um elemento que urge ter em conta.

\section{C - A influência da automação sôbre a concepção e o funcionamento da administração}

Esta influência pode ser razoàvelmente apreciada nos quatro seguintes planos:

- de concepção da administração.

- de eficácia da administração;

- do fator humano; e

- das repercussões gerais.

No plano da concepção, a administração tende a se tornar uma estrutura de funcionamento menos burocrático e mais centralizado. Daí resulta que os aspectos não jurídicos das ciências administrativas parecem apresentar as mais fabulosas perspectivas futuras. Já não é possivel deixar de admitir que as possibilidades de automação reforçarão o caráter técnico dos serviços públicos em uma parte considerável de sua gestão. Na prática, mister se faz prever o aparecimento, nas funções públicas, de um crescente número de técnicos que, em razão de uma estrutura específica de espirito, são de molde a exercer uma certa influência sôbre o melhor aproveitamento e um «entrosamento» entre disciplinas até aqui senão opostas, pelo menos, essencialmente distintas. Esta consequiência pode abrir aos estudos administrativos perspectivas e possibilidades sôbre as quais seria inútil e prematuro'insistir. 
b) no plano da eficiência técnica, a administração passará a dispor de um instrumento de possibilidades pràticamente ilimitadas. A antiga concepção segundo a qual uma administração não tende senão à simples manutenção e continuidade de seus serviços, parece já ultrapassada pela tendência de submeter a administração, em certas de suas atividades, a uma estimativa de produtividade. Em consequiência, surgem novas possibilidades para a reforma administrativa tantas vêzes tratada, inúmeras vêzes aguardada, mas sempre diferida e postergada. Esta é uma constatação básica que foi posta em relêvo durante o Inquérito empreendido. Não se deve, todavia, superestimar ou subestimar essa observação. A experiência mostra que em matéria de administração as conclusões mais lógicas são, muitas vêzes, batidas e anuladas, na prática, por elementos dificilmente redutiveis, os quais são, quase sempre, os fatôres responsáveis pelos fracassos das reformas administrativas. Assim, a mais legitima esperança oriunda da automação funda-se na transformação do «espirito» das administrações liberadas dos entraves que thes condicionavam o funcionamento; essa esperança é mais importante do que a simples fé nos resultados de uma verdadeira revolução técnica.

Diga-se de passagem que esta revolução técnica pode fazer nascer, mais cedo do que se poderia presumir, a transformação unânimemente esperada, uma nova «mentalidade» superior à própria automação.

No plano do fator humano encontra-se a pedra de toque de todo o sistema. Há uma tendência em se exagerarem os efeitos secundários, nefastos, da automação. De boa fé, acreditou-se que a noção de automação (isto é, da exatidão e velocidade) acompanhava a de desemprêgo, chômage, e de redução de efetivos.

Embora tal não ocorra de uma maneira absoluta, é preciso, contudo, admitir que a automação exigirá um certo número de reformas no nivel do pessoal. Essas reformas nem sempre convergem exclusivamente para um desejo de eficiência, objetivo por vêzes colimado com a exclusão de tôda consideração humana ou social.

Haja vista o exemplo do estafante trabalho do pessoal incumbido do funcionamento de certas máquinas contábeis, calculadoras ou tabuladoras. O recrutamento dêsse pessoal tornou-se muito dificil, em certos países. A supressão, pela automação, de empregos dêsse tipo, - vale insistir, duríssimos, - não é desejável sòmente do ponto de vista social; ela pode se transformar em uma necessidade porquanto se torna cada vez mais difícil encontrar pessoas que queiram exercer tais funções. Evidentemente não se deve generalizar e concluir que tôda fase de mecanização ocasionará tais problemas. O fato de que êles existem mostra, todavia, que seria talvez um pouco abusivo considerar o problema do pessoal apenas sob o ângulo exclusivo da redução em número. Esta redução, que é indiscutível e que é talvez, uma das vantagens da automação, não significa que o pessoal deva ser totalmente licenciado. Ao contrário, êsse pessoal poderá ser readaptado a novos encargos ou tarefas, e tudo indica que a redução do pessoal não atinge efetivamente, senão percentagens razoáveis. Parece outrossim que o pessoal poderia ser utilizado, com vantagens, para outros trabalhos até então imperfeitamente efetuados, por ocasião de sua liberação das funções improdutivas, com o advento da automação. 
O reemprêgo do pessoal não se limita apenas às novas necessidades criadas diretamente pela automação. O relatório de M. HATterY acentua que a automação não provoca pràticamente desemprêgo de vulto nos casos em que, simultâneamente se adotam programas rigorosos de planificação administrativa. Deve-se se levar em conta, de uma maneira geral, que a automação se superpõe a uma organização de serviços já amplamente mecanizados, funcionando, portanto, com um pessoal relativamente limitado. Mesmo na eventualidade de uma passagem direta, sem transição. do trabalho manual à automação, uma experiência concreta assinalada pelo Relatório revela que sòmente $25 \%$ do pessoal teve de ser licenciado. Não se deve concluir dêsse fato, no entanto, que o número do pessoal dispensado jamais ultrapasse essa percentagem - limite $(25 \%)$. Efetivamente, o reemprêgo do pessoal que é o único meio de reabsorver os excedentes criados pela automação, - depende do gênero de trabalho dos agentes e também de suas aptidões funcionais a tal ponto que se torna difícil, nesse domínio, chegar a conclusões precisas. É, porém, evidente, que uma readaptação do pessoal é inevitável e que os agentes mais velhos se encontram em condições desfavoráveis em virtude de sua menor capacidade de adaptação às novas circunstâncias; não obstante, o pessoal excedente pode ser ùtilmente reempregado em outras modalidades de trabalho, ou em outras ocupações reveladas pela própria análise preliminar à implantação das técnicas de automação. Já se disse que a automação acarretaria a crescente introdução de técnicos nas funções públicas. No concernente ao seu recrutamento cumpre acentuar que não existe, ainda, nenhuma indicação concreta digna de menção. Sabe-se que será preciso recorrer a novas técnicas de seleção e de formação, mas o estágio das realizações práticas ainda não foi atingido nesse dominio. A Comissão do Serviço Civil, nos Estados Unidos, experimentou operar uma classificação das funções no dominio da automação. Essa tentativa permitiu formular cinco novos grupos de funções, o que representa, até certo ponto, um elemento interessante. No tocante à formação, as indicações oriundas da Inglaterra insistem em que o funcionamento das instalações eletrônicas, contràriamente à opinião generalizada, não exige especialistas cuja formação seria longa e dispendiosa. Citamos os exemplos anglo-americanos porque nesse dois países é que foram levadas ao máximo as conseqüências de uma automação já parcialmente realizada.

A programação, - juntamente com a análise, - é, contudo, a função primordial para o funcionamento eficaz de um conjunto eletrônico. Ela não exige uma formação acadêmica mas postula atitudes especiais e uma preparação prática. Ûm último ponto: o da incidência psicológica da automação nos serviços públicos. Apenas citamo-lo por se tratar de uma matéria assaz difícil, mas de incontestável importância e que deve ser objeto de estudos essencialmente práticos.

No plano das repercussões gerais, em sentido amplo, cumpre estabelecer uma distinção entre os trabalhos administrativos submetidos a regras e obrigações oriundas das leis e aquêles outros trabalhos que, por sua natureza, não lhes estão submetidos ou escapam a essas regras. No quadro das atuais circunstâncias, em face das realizações preliminares da automação, é mais do que evidente que a segunda categoria de trabalhos é manifestamente mais importante pelo número, do que a primeira. 
Várias ocorrências e observações chamam a atenção em alguns Relatórios, para o fato de que a automação, embora implique, obrigatòriamente, uma racionalização do trabalho, pressupõe, ao mesmo tempo, uma modificação preliminar dos processos, em conseqüência das leis e regulamentos que os estabelecem.

A automatização está, pois, condicionada pela racionalização.

Em si mesmo tal fenômeno nada tem de extraordinário. Novos meios técnicos permitem considerar os problemas segundo concepções que não são evidentemente as mais adaptadas às que presidiram à redação e ao estabelecimento de regras quase sempre muito antigas e estratificadas pela tradição. Via de regra, a questão pode ser posta nos seguintes têrmos: ou bem os regulamentos, hábitos e processos são modificados e adaptados às novas condições e possibilidades da técnica, ou, poderá acontecer que a automação se torna infinitamente mais difícil, quiçá impossivel, nos dominios freqüentemente fechados até mesmo à mecanização; pelo menos no presente estágio da automação.

A tendência se manifesta no seio da administração, de exigir a libertação de numerosas tarefas ou funções improdutivas cuja manutenção não oferecia problemas quando os trabalhos administrativos eram manuais e burocráticos; a partir do momento em que êsses mesmos trabalhos devam ser efetuados por instalações muito dispendiosas impõe-se a transformação.

Ainda é demasiado cedo para se apreciar com exatidão e em seu justo valor o alcance e a amplitude destas observações que não constituem senão um aspecto das condições, perspectivas e resultados da automação no âmbito dos serviços públicos.

3. O INQUÉRITO DO INSTITUTO INTERNACIONAL DE CIÊNCIAS ADMINISTRATIVAS. - ANÁlise dos RESUltados CONCRETOS.

Recapitularemos, neste tópico, de uma maneira extremamente sucinta, os principais resultados, em função das respostas ao Questionário elaborado pelo Instituto, reagrupados de acôrdo com os diversos itens nêle tratados. Não se trata de uma revisão geral dos problemas práticos da automação, nem de uma análise exaustiva mas, simplesmente, de uma apreciação global das condições, resultados e perspectivas da automação à luz do referido Questionário.

\section{A - Dominios da administração pública susceptiveis de automação}

1. Muito embora a automação constitua, atualmente, nos domínios assaz variados da atividade administrativa, uma preocupação absorvente, do ponto de vista prático ela está sendo realizada apenas em um número limitado de casos. No estado atual da técnica as experiências de automação mencionadas nos Relatórios se relacionam - em sua quase totalidade. nos casos em que se apresenta, «em um ciclo de execução», «um número elevado de operações de natureza semelhante a intervalos sucessivos».

2. A enumeração constante dos Relatórios dos vários países não é exaustiva. A automação tem sido aplicada de uma maneira relativamente 
arbitrária, à falta de um critério qualquer permitindo o estabelecimento de uma ordem satisfatória de importância entre os elementos que a integram. Quanto às aplicações práticas, logo de saída foi afastada tôda classificação por país, ou com relação ao material utilizado. Assim a apresentação podia ser realizada, seja por tipos de atividades - sem distinção dos serviços públicos interessados - seja, ao contrário, por setor administrativo (em sentido amplo), o que implica, inevitàvelmente, repetições aparentes, apesar das diferenças que podem existir entre problemas à primeira vista semelhantes. É êste ponto de vista que foi de preferência adotado mas não de uma maneira absoluta, certas atividades por muito parecidas sendo reagrupadas sob uma mesma rubrica. Destarte, a enumeração é mais indicativa do campo das possibilidades da automação. Foi igualmente com esta finalidade que se deixou de lado o estabelecimento de uma distinção de base entre as aplicações realizadas e as que se encontram em estudos.

$\mathrm{Na}$ enumeração dos principais casos as aplicações práticas da automação foram respectivamente simbolizadas pelas letras $R$ e $E(A p R)$ e $(\mathrm{Ap} E)$ - isto é, aplicação Realizada e aplicação em Estudos. Ainda uma observação: o Relatório da Inglaterra, mesmo dando informações precisas sôbre as experiências adquiridas em cêrca de vinte casos de aplicação e de número quase idêntico de aplicações em andamento ou estudo, não indica, contudo, quais os problemas que foram abordados.

Ao contrário, o Relatório dos Estados Unidos apresenta, em detalhe, um número considerável de realizações ou de projetos que é impossivel citar integralmente; sòmente foram considerados os casos mais típicos.

3. De acôrdo com o Inquérito, são susceptiveis de automação notadamente os seguintes dominios:

a) Operações financeiras - tomadas em uma acepção bastante ampla do têrmo sem que seja necessário indicar ou enumerar quais os serviços públicos interessados, nem o número de aplicaçóes realizadas $(A \mathrm{p} R)$ ou em estudos $(A \mathrm{p} E)$.

Países - Bélgica $(A p R)$; Estados Unidos $(A p R)$; Finlândia $(E)$; França (R); Irã (R); Japão (R); e Holanda (R).

Principais aplicações; - cálculo e liquidação de pagamentos, salários ou pensões; - manutenção em capital e juros de contas correntes, ou depósitos, assim como os registros ou contrôles que os afetam; - verificação e ajustamentos de cheques; - cálculos fiscais.

\section{B) Administração das comunicações}

1. $\left.{ }^{\circ}\right)$ correios, telégrafos e telefones.

Paises - Austrália (ApE); Bélgica (ApE); Estados Unidos (ApR); França (ApE) e Holanda (ApE).

Principais aplicações: - impostos e taxas. «redevances» (percepção e contrôle): - pagamentos de pessoal - gestão dos estoques de material; gestão dos serviços radioelétricos.

2\%) Rêdes ferroviárias.

Paises - Bélgica (ApE); França (ApE); Itália (ApR). 
Principais aplicações: - movimento do material rodante; - contrôle e gestão do transporte de mercadorias. (Êste problema concerne, por exemplo, na Bélgica, 13.000 expedições diárias representando 4.000 .000 de operações anuais e o estabelecimento de 3.000 faturas por dia)

3?) Aviação civil.

Países: - Estados Unidos (ApR) e França (ApE).

Principais aplicações: - movimento dos aparelhos em vôo; - centralização das reservas; - gestão e contrôle dos estoques, peças sobressalentes e material.

c) Administração Militar. (ApE).

Paises: - Estados Unidos (ApR); França (ApR) e (ApE); e Holanda

Principais aplicações: - cálculo e liquidação de soldos; - gestão e contrôle dos estoques; - gestão e contrôle de peças sobressalentes e de substituição.
d) Administração financeira.

1\%) Contribuições Diretas.

Paises: - Bélgica (ApE) e Pôrto Rico ( $\mathrm{ApE}$ ).

Principais aplicações: - cálculo e contrôle anual em matéria de contribuições financeiras; - Impôsto sôbre a Renda.

2:) Tesouraria, Divida Pública e Pensões.

Países: - Bélgica (ApE); Estados Unidos (ApR); França ( $A p E)$; Japão $(A p R)$; Holanda ( $A p E)$ e Pôrto Rico ( $A p E)$.

Principais aplicações: - cálculo e pagamento de salários, indenizações, pensões ou alocações; - contrôle das contas e operações de contabilidade pública; - divida pública; - pensões civis, militares ou de guerra (modificações indexadas ou perequações barêmicas).

3. Cadastro.

Pais: - Bélgica (ApE).

Principais aplicações: - atualização anual dos documentos cadastrais (elaboração de dossiês de mutações, verificação, transcrição das mutações e verificações, confecção de livros diários; - trabalhos diários de rotina (entrega de sumários); - trabalhos periódicos (renovação das matrizes); - trabalhos excepcionais (mise-en-application da perequação cadastral).

e) Administração Agricola.

Países: - Estados Unidos (ApR e ApE) - (Commodity Stabilization Service).

Principais aplicações: - inventários e contabilidades (cereais e algodão); - vigilância e fiscalização dos estoques. 
f) Seguros Nacionalizados.

País: - França (ApR e ApE).

Principais aplicações: - quittancement à terme; - estatistica; - tarıfação; - cálculos atuariais; - gestão.

g) Diversos:

- Tratamento das Estatísticas: Austrália (ApR); Estados Unidos $(A p R)$; França $(A p R)$; Israel (ApR); Iugoslávia (ApR).

- Pesquisas Operacionais : Estados Unidos (R).

- Recenseamento: - Israel (R).

- Pesquisas Científicas: Estados Unidos (R); França (E).

- Estado Civil e Serviços de Identificação: Itália (R).

- Meteorologia: - Estados Unidos (R) - (Estabelecimento de cartas. mapas e conservação de dados anteriores).

\section{$B$ - Número de operações por assunto e número de operações anuais}

É difícil situar o número-limite dos casos tratados por ano, abaixo do qual a automação parece deixar de ser mais produtiva. $O$ Inquérito mostra que o número minimo dos casos tratados anualmente é da ordem de 400.000 e o máximo de 450.000.000. O número de operações próprias e adequa. das a cada caso varia entre 3 e 24 .

Admitem os relatores, em geral, que é mais econômico possuir um conjunto eletrônico de uma grande envergadura do que vários conjuntos de menor capacidade.

Surge, então, um problema de centralização tendo em vista que sempre é possivel instalar um conjunto eletrônico para vários serviços, departamentos ou ministérios. Os «teleprinters» permitirão uma centralização mais avançada em razão de suas possibilidades de impressão à distância de resultados obtidos em instalações importantes e centralizadas. Contudo, esta centralızação talvez tècnicamente desejável e certamente exeqüivel, se choca, por vêzes, com perigos e dificuldades durante as aplicações práticas.

C - Execução anterior das tarefas (manuais ou mecânicas) e efeitos da automação. Experiências típicas na Bélgica, nos Estados Unidos e na Holanda

1. Salvo exceção, a automação jamais se realizou mediante passagem direta do nivel do trabalho manual à instalação de um conjunto eletrônico. A automação, regra geral, representa a última etapa de uma mecanização muito adiantada nos serviços, mecanização à qual ela se superpõe, completa ou substitui. Isto não deve fazer perder de vista que a automação, graças às suas possibilidades inerentes, poderá atingir domínios nos quais a mecanização era pràticamente irrealizável ou pouco produtiva. Com o avanço da automação em setores até há pouco tempo refratários à própria mecanização, crescem as possibilidades de transformação e produtividade.

2 - As transformações ou mudanças - geralmente diminuição - do equipamento em seguida à instalação de um conjunto eletrônico são sensi- 
veis. Para ilustrar êsse fato merecem ser citados alguns casos específicos apurados pelo Inquérito :

a) Bélgica: (Ferrovias)

- a tarefa anteriormente à automação era executada por:

20 perfuradoras; 17 verificadoras; 15 separadoras; 2 calculadoras; 10 tabuladoras; 6 intercaladoras; 6 reprodutoras; 2 interpretadoras; 6 perfuradoras de recapitulação. pamento:

- a tarefa se executa no momento por meio do seguinte equi-

1 ordenador de potência média; 2 perfuradoras conectadas; 1 tabuladora conectada.

b) Estados Unidos: (pagamentos e ajustamentos de cheques)

- a tarefa era anteriormente executada por:

30 perfuradoras; 10 verificadoras; 120 selecionadoras; 125 tabuladoras. 6 calculadoras. mento:

- a tarefa está sendo executada por meio do seguinte equipa-

1 «705» Modêlo II System (IBM)

c) Holanda: (Pagamentos, verificações, contrôles)

- a tarefa era anteriormente executada por:

8 perfuradoras; 5 perfuradoras-controladoras; 5 selecionadoras; 3 calculadoras; 1 perfuradora de recapitulações; 4 tabuladoras; 1 calculadora elétrica. pamento:

- a tarefa está sendo executada por meio do seguinte equi-

1 IBM 650.

4. ESTUDO PRELIMINAR - INTERVENÇÃO DE COMITÊS ESPECIAIS

$$
A \text { - Concepção e Composição }
$$

Os estudos preliminares à implantação da automação são efetuados, conduzidos ou coordenados, regra geral, por Comitês Especiais. (A composição dêsses Comitês não corresponde, em principio, a nenhuma regra fixa e é tributária das circunstâncias; ela mereceria, por si só, um estudo especial principalmente no concernente aos Comitês Técnicos). Pode-se levar a efeito quanto aos Comitês Especiais uma dupla distinção;

1) Os Comitês que trabalham no plano da politica geral a seguir, em matéria de automação.

A concepção que preside à instituição dos Comitês dêsse tipo é extremamente variada. Citaremos, a título de exemplo, a criação, em 1955, no Canadá, de um «Comitê Interministerial para a Eletrônica». Êsse Comitê (composto de um Presidente e de dez funcionários superiores representando cada um o seu Ministério ou Departamento) tem por finalidade assegurar a 
coordenação do estudo dos problemas da automação na administração federal. Êle estuda o desenvolvimento da automação nos serviços públicos e examina as solicitações provenientes dos diversos Ministérios ou Setores em face da instalação de conjuntos eletrônicos.

Os Relatórios franceses e italianos, de seu lado, examinam o problema num plano mais vasto. Êles consideram, segundo a feliz expressão dos relatores franceses, que «preconizar e executar uma politica de automação na administração pública é uma operação que sòmente poderá ser resolvida de cima para baixo, pelas Autoridades superiores. A transformação das estruturas, dos métodos e dos processos, assim como as adaptações legislativas e regulamentares necessárias, exigem uma autoridade que pode ultrapassar até mesmo o quadro ministerial: é, pois, o próprio Govêrno que deve tomar a decisão - e é o Presidente do Conselho - ou o seu Delegado quem lhe garante a execução. O Parlamento, em virtude das modificações legislativas e das incidências orçamentárias correspondentes, está estreitaniente associado à operação».

Se bem que esta concepção não se apóie, por enquanto, em nenhuma realização prática, ela traduz uma incontestável necessidade a partir do momento em que a automação atinge um desenvolvimento mais importante do que atualmente. Ela permite igualmente dar ênfase ao aspecto financeiro dos programas de automação. A instalação de conjuntos eletrônicos, que se justifica tècnicamente, acarreta, porém, despesas assaz importantes; há tôda conveniência em que êste elemento seja comparado com as vantagens que se espera obter da automação. Reunidas tôdas as condições técnicas preliminares, impõe-se, então, resolver os problemas da oportunidade com relação aos investimentos a realizar. Òbviamente, tais problemas sòmente serão resolvidos de cima, pela cúpula (um órgão de nível superior, eventualmente um Comitê Especial). Deve-se observar que o Comitê Interministerial canadense parece bem desempenhar uma função dêsse gênero. Ȧ medida que a automação se estender e progredir, os fatos verificarão sem dúvida as vantagens de semelhante método, além das formas institucionais adotadas.

2) Os comitês que agem no nivel da apreciação técnica - Os comitês deste tipo se atribuem como encargo primordial o exame das questões de natureza técnica e prática decorrentes de um programa de implantação eletrônica em um serviço, departamento ou ministério. No Canadá, como desdobramento do Comitê Interministerial já mencionado, foi instituido um Comitê deste gênero no âmbito dos serviços O \& M (Organização e Métodos) da Civil Service Comission.

$\mathrm{Na}$ Inglaterra as pesquisas técnicas preliminares são conduzidas pelos referidos serviços de Organização e Métodos $(\mathrm{O} \& \mathrm{M})$, Ministério interessado ou, na ausência dêstes, pela Divisão de Organização e Métodos ( $\mathrm{O}$ \& M) do Tesouro (H. M. Treasury).

Para a Bélgica, no tocante ao Ministério das Finanças, foi constituído um Grupo de Estudos (constituído de Delegados dos contribuintes, do cadastro, das pensões, do Tesouro, e dos serviços de O \& M - Organização e Métodos - do Secretariado Geral).

Poder-se-iam multiplicar os exemplos de um tal método de ação. Comitês ad-hoc não intervêm senão excepcionalmente. Entre as respostas recebidas 
podem-se citar pois casos nos quais as pesquisas preliminares foram conduLidas sem o recurso a tais Comitês e, ao que parece, exclusivamente pelos técnicos da firma fornecedora dos equipamentos e aparelhos. Êsse processo não parece ter sido admitido senão quando a instalação de um conjunto eletrônico não implicava em nenhuma reforma de estrutura ou modificações importantes dos métodos de trabalho, as tarefas a executar sendo, além disso, limitadas e bastante simples.

\section{$B-M o d o s$ de ação}

Consideraremos apenas o trabalho dos Comitês Técnicos. Caso típico é o do Canadá onde, como se sabe, os estudos técnicos preliminares são confiados, da mesma maneira como na Inglaterra, aos serviços de Organização e Métodos $(\mathrm{O} \& \mathrm{E}$ ). Na Inglaterra estes Comitês, a fim de bem se desincumbirem dos respectivos encargos, criaram um "Comitê de Eletrônica» composto de quatro funcionários de seus serviços, dos quais dois engenheiros especializados em eletrônica. O mencionado Comitê efetuou pesquisas em onze departamentos centrais dos principais ministérios tendo em vista a implantação da automação nos referidos Ministérios. Sòmente em quatro casos é que o Comitê admitiu que a administração pudesse recorrer à automação; nos outros casos a reforma dos métodos de trabalho ou das estruturas, deveria, aos olhos do Comitê, permitir realizar o trabalho com a mesma eficiência que a desejada, sem automação. No máximo, em certas eventualidades, considerou-se a possibilidade de alugar instalações, inclusive de firmas privadas.

2 - A missão dos Comitês consiste simultâneamente em provocar direta ou indiretamente - os melhoramentos necessários ao funcionamento dos serviços; não se negligencia, de forma alguma, tudo quanto possa con-ribuir para a obtenção dêsse fim.

A êste respeito é interessante assinalar que na Bélgica, o Grupo de Estudos do Ministério das Finanças - que não é exclusivamente constituído de especialistas em automação - seguiu, durante três semanas, cursos de formação elementar na utilização de equipamentos eletrônicos. Parece oportuno resumir as conclusões que se impuseram unânimemente em conseqüência e como resultado dêsses cursos:

I - A velocidade e a eficiência do trabalho dependem das possibilidades dos aparelhos e do equipamento mas, igualmente e sobretudo, da exploração dessas possibilidades por uma cuidadosa programação.

II - A programação deve examinar, passo a passo, todos os fatôres e minúcias que podem intervir nos trabalhos. A mais insignificante operação, esquecida ou mal anotada, na análise, conduz a resultados falsos. Esta detalhada análise das operações administrativas é indispensável, qualquer que seja a solução eletrônica eventual.

III - Cada detalhe deve ser examinado com atenção a fim de ser determinada sua razão de ser. Estas análises devem permitir simplificar, rearranjar, reagrupar, ou combinar cada detalhe cuja necessidade se impõe para que se possa chegar a um melhor andamento de trabalho, simples e lógico, compreendendo tudo o que fôr preciso e sòmente o que fôr preciso. 
Observe-se que essas análises não podem ser conduzidas exclusivamente sob o ângulo do rendimento, ou seja, do ponto de vista da pura produtividade; elas também devem levar em conta certos imperativos de ordem jurídica, ou simplesmente legislativa, que condicionam o trabalho. Alguns Relatórios demonstram nitidamente que a solução dos problemas técnicos é complicada - senão entravada - pela existência de regras ou de processos legais inadaptados às necessidades da vida moderna.

3 - Sôbre um plano mais geral, o método seguido na Inglaterra é um exemplo que poderia ùtilmente servir de modêlo ou inspiração, porque a prática confirma sua adaptação às necessidades. No exemplo inglês se podem distinguir três etapas:

I - Determinação da Utilidade. Quando se Justifica a Utilização de Um Conjunto Eletrônicọ.

Durante essa fase empregam-se esforços para definir com precisão a extensão de seu campo de aplicação. A análise que deverá levar à decisão diz respeito igualmente à possibilidade de transformar a estrutura do departamento tendo em vista sua melhor adaptação ao trabalho colimado. No término dessa fase a decisão é tomada e, uma vez determinada a utilização, várias firmas são convidadas a submeterem os seus preços.

II - A Seleção e a Formação do Pessoal Necessário ao Funcionamento da Nova Estrutura Adotada.

A seleção se opera, em primeiro lugar, em todos os níveis, com relação aos antigos agentes susceptiveis de se adaptarem às novas tarefas e métodos de trabalho, mediante um periodo de formação. A seleção deve ser tanto mais ampla quanto ela se fundamenta em critérios novos, pondo em relêvo, não preferentemente as capacidades gerais dos candidatos, senão, também, suas aptidões especiais sobretudo para a função da programação. Apenas subsidiàriamente e na ausência de outras soluções é que se recorre a contribuições do exterior. Os fatos confirmam êste ponto de vista quando se considera que o pessoal pode igualmente ser reempregado ou utilizado em outras tarefas até então relativamente negligenciadas, ou em funções novas, sem relação com a automação.

\section{III - A reorganização dos métodos de trabalho}

Essa reorganização se efetua preliminar e progressivamente à instalação definitiva das máquinas na medida em que o trabalho precedente é substituido pela automação ou quando esta intervém. Cumpre observar que esta transição será evidentemente tanto mais delicada quanto a passagem de um sistema para outro fôr mais profunda. Deve ser considerada, em certos casos, a eventualidade de um trabalho paralelo e simultâneo, das suas instalações ou sistemas (o antigo e novo) durante um certo período.

\section{ESTUDO PRELIMINAR - DURAÇÃo}

As respostas indicam que os estudos preliminares duram de 1 a 4 anos; todavia, de uma maneira geral, pode-se admitir uma medida de cêrca de três (3) anos. A amplitude e duração dêstes estudos são uma função 
de sua complexidade como, também, do grau de iniciação prévia dos funcionários dos serviços interessados nas possibilidades e técnicas da automação. A experiência parece, com efeito, ter provado que o estudo não pode ser efetuado com sucesso senão por um conjunto de pessoas entre as quais as competências na matéria própria do serviço, e as competências no domínio da automação, desempenham papel igualmente importante. Esta duração se justifica pela extrema prudência que é preciso fazer prova e pela minúcia das análises preliminares. Isto sem contar que a instalação de um conjunto eletrônico inspira tanto as reformas jos métodos de trabalho como as de estruturas. Os inconvenientes da relativa amplitude e demora dos estudos preliminares são largamente compensados pela certeza de que a automação sòmente atingirá a plenitude dos seus objetivos nos casos em que sua implantação haja sido excepcional e cuidadosamente preparada.

Ainda não é possivel deduzir os elementos de um processo-tipo susceptivel de evitar as excessivas demoras no exame, embora eliminando, por completo, as possibilidades de êrro. Cada caso se apresenta, via de regra, com características peculiares, sendo, pois, mais ou menos específico.

As indicações já formuladas esclarecem a conveniência de levar em conta o periodo de transição que se segue à instalação definitiva, de duração variável e que se não considerou na estimativa da duração dos estudos preliminares. Cumpre, outrossim, ajuntar às demoras indicadas não sòmente êste periodo de transição, como, também, um certo lapso de tempo para uma adaptação definitiva às novas técnicas.

\section{ESTUDO PRELIMINAR. EVENTUALIDADE DE UMA REORGANZAÇÃO}

IMPORTANTE DOS SERVIÇOS

A ser considerada como inevitável esta reorganização, miter se faz distinguir entre a simples reorganização dos métodos de trabalho e uma reorganização mais vasta, atingindo os processos e as estruturas. Enquanto que a primeira sempre está presente, a segunda apenas aparece em determinadas circunstâncias, sendo o seu alcance sumamente variável. Note-se, porém, como princípio, quanto mais mecanizada tenha sido a organização no precedente estágio, tanto menos extensas serão as reformas decorrentes da automação. (Poderão ocorrer exceções, naturalmente)

No Irã, por exemplo, a reorganização posterior a uma implantação de automação abrangeu exclusivamente a simplificação do trabalho, pela fusão de várias operações em uma só, nenhuma reforma de estruturas havendo sido empreendida.

No Japão, pelo contrário, a automação teve por efeito permitir uma reorganização no escalão horizontal por uma centralização sendo suprimidos os serviços periféricos. Os exemplos que se poderiam tirar das experiências e dos estudos americanos, franceses, ou holandeses, mostrariam, igualmente, que segundo a natureza dos serviços ou do trabalho a automatizar, as reformas são, ora de estrutura, ora de métodos, ora simultâneas.

A priori, torna-se difícil determinar em que casos haverá reforma em um ou outro dos mencionados dominios. Considerando-se apenas as refor- 
mas importantes é evidente que têm prioridade as reformas de estruturas. A própria noção de «reforma de estruturas» não deve ser tomada exclusivamente como incidindo sôbre a organização dos serviços; ela pode se referir às reformas necessárias nos planos legislativo e regulamentar.

Os estudos de automação fazem sobressair, com frequiência, certas incoerências da legislação, às vêzes muito antigas, ocasionadoras de formalismos inúteis que entravam o trabalho administrativo. Pode acontecer que uma reforma legislativa seja indispensável ao êxito da automação. É uma tal evidência que, em medida não negligenciável, justifica a distinção que efetuamos entre as missões entregues aos Comitês encarregados da direção ou da coordenação dos estudos prévios.

Do ponto de vista dos fatos, vários Relatórios - quer nacionais, quer referentes a uma determinada aplicação - insistem acêrca da extensão ou amplitude a dar ao conceito «reforma de estruturas». Em conseqüência, desnecessário se torna dissimular as dificuldades dai resultantes e que se acrescentam às de ordem humana ou psicológica.

\section{CONSULTA ÀS DIVERSAS FIRMAS FORNECEDORAS DOS EQUIPAMENTOS ELETRÔNICOS}

Parece incontestável que o principio de uma vasta utilização dos apelos e ofertas é sempre respeitado. Tal atitude é indispensável e deve muitas vêzes extravasar os limites dos produtores nacionais. Podem os pedidos ou oferecimentos serem feitos ao exterior. O recurso a êste processo permite determinar com certeza qual é o equipamento que apresenta as melhores «equipamento-padrão» as máquinas necessárias à execução dos trabalhos a precioso concurso dos técnicos das firmas interessadas. A matéria apresenta tanto maior importância, quanto é certo nem sempre ser possivel encontrar no «equipamento-padrão» as máquinas necessárias à execução dos trabalhos a automatizar. Adaptações por vêzes se revelam indispensáveis e a cooperação de várias firmas, ou de uma dentre elas, é extremamente útil. Cumpre assinalar que certas operações são de tal forma específicas que é necessário fazer construir novas máquinas para realizá-las de uma maneira prática. O caso das «comptes-chèques postaux», na Bélgica, demonstra-o nitidamente. Antes de chegar a uma tal decisão, claro que vale a pena passar em revista todos os equipamentos existentes no mundo.

\section{UTILIZAÇÃO DAS MÁQUINAS}

1 - Sôbre êste ponto as respostas sâo muito variadas e urge adotar uma classificação.

a) A Utilização (excepcional ou regular) de um Conjunto Exterior ao Serviço.

(Mesmo que êste conjunto esteja em funcionamento em um outro serviço ou departamento, em uma firma privada ou, como em caso aliás excepcional, no estrangeiro, em vista da realização de um trabalho corrente.) No plano prático, sòmente a utilização de um conjunto de um outro serviço ou departamento requererá a atenção. Não sendo excepcional ela apresenta 
múltiplos problemas estreitamente ligados à eventualidade de uma centralização da execução de certas operações. Esta centralização parece desejável quando se considera, de um lado, que uma grande instalação é mais vantajosa (produtiva) que duas médias, e, por outro, que as operações a efetuar nem sempre justificam a «utilização-ótima» de uma instalação própria.

$\mathrm{Na}$ realidade, porém, - e se não se tratar de uma utilização excepcional - esta centralização se choca contra a dificuldade de estabelecer um plano racional de trabalho que seja efetivamente respeitado. A ordem de execução das operações pode dar lugar a controvérsias entre dois ou mais serviços interessados e se esta dificuldade está ausente o programa sempre pode ser tumultuado pela obrigação de empreender trabalhos prioritários. Podem resultar, então, perdas de tempo e desordem nos serviços a menos que a instalação centralizada não disponha de uma capacidade de trabalho que não é senão parcialmente utilizável.

A utilização de uma instalação central, ou externa, nem sempre apresenta tais inconvenientes, mas parece que, no momento, procura-se apelar para o emprêgo da instalação própria que, em numerosos casos, se impõe como a melhor solução. Afigura-se, de fato, difícil e freqüentemente dispendioso, alugar perpètuamente um equipamento no exterior, ou utilizar o equipamento de um outro serviço, salvo em circunstâncias especiais.

Se a centralização é teòricamente sedutora - e quiçá realizável mediante uma perfeita organização do plano de trabalho - ela se choca, em verdade, com dificuldades práticas que, em virtude de sua importância, não podem ser negligenciadas. Algumas questões incidentais levantadas em um Relatório francês, são de molde a esclarecer problemas que, na eventualidade de uma automação mais «centralizada e desenvolvida» adquirirão, sem dúvida, grande importância. As questões podem ser formuladas da seguinte maneira: que medidas são tomadas a fim de atender aos inconvenientes de um desfalecimento (défaillance) nos serviços de manutenção e reparos? (assegurados, em princípio, pela firma vendedora). Quais as providências na hipótese da ocorrência de tumultos sociais (greves do pessoal vinculado aos serviços de manutenção), ou de uma interrupção das comunicações entre o país de origem (quando o referido conjunto não é construído no país que o utiliza) em seguida a uma crise internacional qualquer? $O$ que poderia ocorrer se essa crise provocasse uma falta de peças sobressalentes?

Embora tais problemas ainda não se apresentem de uma maneira sensivel, é fora de dúvida que nêles se contêm possibilidades enormemente importantes; a simples apresentação de tais problemas basta para mostrar até que ponto são levados os raciocínios teóricos.

Abstração feita de influências oriundas da crise internacional - a qual deve ser encarada como uma exceção - a paralisação eventual do funcionamento de uma instalação (em conseqüência de uma greve do pessoal encarregado da manutenção e dos consertos) não pode ser - no plano teórico - negligenciada. Ou subestimada.

De uma maneira muito geral afigura-se que o desenvolvimento da automação nos serviços públicos postula, do mesmo passo, uma libertação de certas dependências ou subordinações externas. Desde que a necessidade se manifesta, a administração talvez tenha interêsse em dispor, em seu seio, 
de técnicos capazes de assegurar a continuidade do serviço, quaisquer que sejam as circunstâncias, ou de tomar tôdas as precauções para tal fim. Citamos expressamente tais problemas a fim de ilustrar a multiplicidade de aspectos que urge levar em conta quando se fala de automação. E um dêsses aspectos é, precisamente, a dependência do exterior.

b) Utilização de Uma Instalação Exterior para Verificação dos Resultados dos Estudos Preliminares.

1 - Neste caso os problemas diferem pois que ela é temporária: - a utilização aparece como muito oportuna, principalmente quando se trata de assegurar a concordância das conclusões teóricas dos estudos com os resultados práticos obtidos pelo equipamento proposto por uma firma; ou de verificar certas possibilidades de utilização.

2 - De uma maneira conexa pode-se, ainda, lembrar duas questões: a) a utilização interna de uma instalação experimental durante um período mais ou menos longo, - por aluguel, por exemplo - com o objetivo de perfeita «mise-au-point», em nível prático, de um projeto tendo ultrapassade o estágio dos estudos preliminares.

Trata-se de uma modalidade especial de verificação de dados teóricos, merecedora de atenção, no caso em que as soluçôes são complexas e exigem uma adaptação impossivel sem que efetivamente seja posta em funcionamento uma instalação. (Esste sistema é notadamente aplicado, em um caso preciso, na França; êle revela um rigoroso cuidado de exatidão e uma vontade de sòmente agir com plena certeza).

b) Utilização paralela ou simultânea, durante um certo tempo, da mecanização e da automação, quando esta última é chamada a substituir integralmente àquela. Verifica-se então uma duplicidade na execução de tôdas as operações; diga-se de passagem que tal sistema aplica-se apenas em caso de necessidade e durante um período de transição. Ele apresenta vantagens e também inconvenientes mas pode se impor como inelutável. A título de exemplo, assinalemos que os «comptes-chéques postaux) belgas, a vista das circunstâncias especiais, optaram por uma solução comportando (a) o funcionamento durante cêrca de quatro meses, de um equipamento pilôto (visivel na Exposição de Bruxelas - Palácio das Telecomunicações) e $(b)$ o funcionamento paralelo, durante 6 meses, (no seio dos próprios «comptes-chéques») do antigo sistema mecanográfico.

\section{CONCLUSÕES}

1. Não se poderia concluir melhor esta sintese das respostas recebidas do que reconhecendo quanto, de uma maneira geral, admite-se a próxima introdução da automação nos serviços públicos. Considerada por muitos, há apenas alguns anos, como uma utopia, e por outros como uma simples etapa no processo da mecanização, a automação aparece hoje como um elemento novo - quase revolucionário - cuja fôrça de penetração é tal que os Estados modernos dela já não mais poderão se afastar ou privar, durante muito tempo. A automação é uma realidade concreta que não se pode mais dispensar. As autoridades responsáveis esperam, cada vez mais, encontrar na automação o meio atualmente melhor adaptado para resolver uma parte 
das dificuldades inerentes à gestão de seus serviços. $O$ quadro abaixo, baseado nas indicações recebidas relativamente à cêrca de 150 casos, dá uma preciosa informação quanto às razões que motivaram, pela ordem, o emprêgo crescente da automação.

\section{ALGUNS MOTIVOS DETERMINANTES DO EMPREGO DA AUTOMAÇAO}

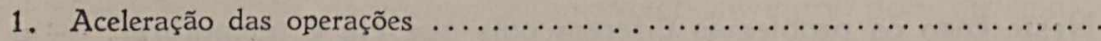
$16,55 \%$

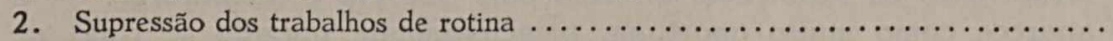
$15,17 \%$

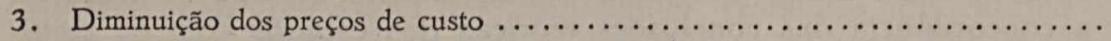

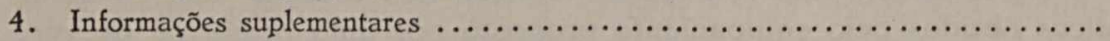
$13,79 \%$

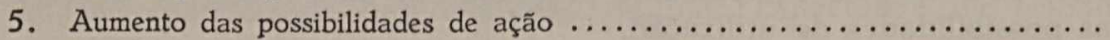
$11,79 \%$

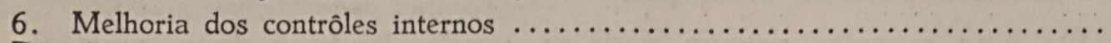
$11,03 \%$

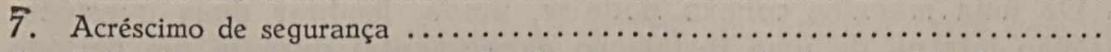

8. Falta de mão-de-obra; desejo de liberar uma mão-de-obra qualificada; huma-

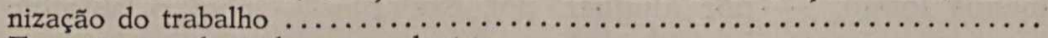

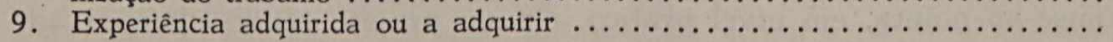

Êste levantamento dispensa maiores comentários a não ser para assinalar que as numerosas razões citadas são, via de regra, concomitantes. Elas dão ênfase às considerações práticas que traduzem um manifesto desejo de melhorar e de facilitar o trabalho administrativo. O elemento humano intervém, por igual modo, confirmando-se, destarte, a tendência geral de humanizar o trabalho em tôda a medida do possivel; de acudir à falta de pessoal qualificado (ou porque seja de qualidade mediocre ou porque seu recrutamento se apresenta difícil); ou ainda de reempregar em outras tarefas uma mão-de-obra especializada tornada disponivel pelo advento da automação. Nenhum fator se destaca nitidamente do conjunto: todos intervêm sempre, - uns mais, outros menos, - em cada caso.

2. Quanto ao programa futuro quase tôdas as respostas recebidas pelo Instituto insistem no interêsse, e conveniência, de ser a automação mantida na Ordem do Dia das futuras reuniões da Entidade. Supere-se a necessidade do Instituto reforçar suas atividades quanto à automação, tanto no plano da informação quanto no da pesquisa terminológica. A êste respeito o Inqué. rito pôs em evidência dos outros elementos que apresentam um interêsse capital do ponto de vista dos futuros trabalhos do Instituto Internacional de Ciências Administrativas: - o primeiro é o número relativamente reduzido das aplicações integralmente realizadas, na hora atual, correlacionadas com o número pouco elevado dos projetos em vias de estudo ou de execução concreto; - o segundo, é a complexidade de cada problema e de sua respectiva solução; complexidade que torna particularmente difícil o estudo, e bastante árduo o confronto com as realizações estrangeiras.

Se o primeiro elemento favorece as permutas, o intercâmbio de publicações e de documentação, - o segundo, pelo contrário, realça-lhes as dificuldades ocorrentes sempre que se pretende penetrar nos detalhes da aplicação. No vasto campo da automação cada caso deve, com efeito, ser considerado como parte de um todo; cada solução adotada depende de um con- 
curso de circunstâncias e obrigações que dificilmente se podem descrever nos limites de um sucinto Relatório. Além do mais, a compreensão das soluções pressupõe o exato conhecimento, não apenas das possibilidades técnicas dos equipamentos como também da legislação, da regulamentação e dos processos aplicáveis aos casos em aprêço.

Uma das tarefas da Mesa Redonda de Liège constitui em proporcionar aos dirigentes do Instituto indicações acêrca dos meios a serem utilizados, tanto pelas seções nacionais, como pelos Comitês e Serviços permanentes, a fim de permitir ao Instituto Internacional de Ciências Administrativas bem desempenhar o seu papel em um domínio cuja importância para os serviços públicos avulta cada vez mais.

II - SEgunda PARTE

Mesa redonda de Liège e os problemas da automação na Administração Pública

\section{1. os relatórios Starreveld e Hattery}

A primeira sessão de trabalho dedicada aos problemas da automação no âmbito da administração pública, em Liège, teve lugar no dia 28 de junho de 1958, sábado, e foi dedicada a uma exposição introdutória, de natureza técnica, formulada pelo Delegado da Holanda M. Starreveld.

A discussão geral dos problemas da automação prosseguiu na sessão de 30 de junho, segunda feira. Incumbiu-se da exposição preliminar o Delegados dos Estados Unidos, Mr. Lowell Hattery. O representante norte. americano à Mesa Redonda de Liège, Mr. Lowell Hattery, deu ênfase. em sua exposição, aos três seguintes aspectos em tôrno dos quais se travaram os principais debates de Liège:

\section{A - O problema do pessoal eventualmente substituido pela introdução dos conjuntos eletrônicos nos serviços públicos}

Trata-se de um problema essencial. De resto, a principal preocupação dos responsáveis pela introdução da automação, nos Estados Unidos, tem sido a de averiguar qual a redução de pessoal que a automação forçosamente acarretaria. Justifica-se plenamente tal preocupação quando se compara a quantidade de trabalho que pode ser realizado por um conjunto eletrônico com idêntica quantidade levada a efeito pelos trabalhadores manuais. Impõe-se, portanto, saber até que ponto surgem os perigos de "chômage» e quais as proporções do presumido desemprêgo decorrente da implantação das técnicas da automação.

A experiência americana, apesar de ser ainda limitada, mostra que não se deve temer o desemprêgo mencionado; como decorrência da introdução de conjuntos eletrônicos a experiência americana permite afirmar que tais perigos são de pouca monta. Esta afirmação se apoia nas seguintes razões: I - Uma planificação preliminar da instalação se efetua tendo em vista, não sòmente os aspectos técnicos da automação, como, também, as questões de pessoal. Esta planificação é tanto mais exeqüivel quanto é certo que decorre um periodo de tempo relativamente longo, entre o momento em 
que se toma a decisão de realizar as instalações e o da implantação definitiva. Do ponto de vista de pessoal, a planificação permite a reutilização ou a reclassificação do pessoal normalmente empregado antes do recurso à automação. A experiência demonstra que nunca faltam tarefas que podem ser confiadas ao pessoal tornado disponível, mesmo quando as referidas tarefas estão direta ou indiretamente ligadas às necessidades da automação; II - Nos Estados Unidos a automação sucede geralmente, a um estágio de mecanização avançada dos serviços (quase sempre trabalho sôbre cartões perfurados), ela ocorre e se superpõe à referida mecanização. Conforme os dados da experiência, é relativamente pequeno o número de pessoas necessárias para assegurar o funcionamento dos serviços nas hipóteses consideradas. Com efeito, o pessoal já familiarizado com a mecanização é preparado de maneira relativamente fácil para as novas funções decorrentes da automação; III - Acontece, freqüientemente, que um periodo de transição ou de funcionamento paralelo da mecanização e da automação permite proceder-se a uma útil reorganização das funções de pessoal de tal forma que os agentes têm o tempo de se adaptarem e de encontrar o seu novo lugar na organização; IV - A importância dos trabalhos de escritório cresce continuadamente; a instalação da automação não pode eliminar êsse fenômeno. Decorrerão cinco ou dez anos, no mínimo, antes que a real influência da automação se faça sentir sôbre esta situação. Por conseguinte, ainda não se pode dizer que o problema encontrou uma solução definitiva. De qualquer forma, pode-se afirmar que a automação - no tocante à redução em pessoal - não provocará tão cedo as conseqüências previstas por alguns.

\section{B) O problema do pessoal incumbido de assegurar o funcionamento das instalações eletrônicas}

Tôda implantação de uma nova técnica dá origem, necessàriamente, a problemas de recrutamento do pessoal capaz de utilizar com eficiência os equipamentos e instalações recém-introduzidos. Quanto à automação ainda não se chegou a um acôrdo relativamente aos seguintes pontos: a) saber como selecionar o pessoal adequado à automação; b) quais as matérias nas quais cumpre especializá-lo.

Esta incerteza se deve à enorme dificuldade existente entre as necessidades de pessoal especializado no funcionamento dos conjuntos eletrônicos as relativas a tôdas as técnicas anteriores. Apesar destas dificuldades a Civil Service Comission fêz esfôrços no sentido de classificar e definir as novas funções nascidas da automação. Os resultados obtidos levaram-na a agrupar as novas funções em cinco (5) categorias:

1 - «Management Analyst», cuja função é objeto de uma descrição pormenorizada, comporta essencialmente a «mise-ou-point» dessa delicada fase que é a programação, considerada esta, sobretudo, do ponto de vista da análise.

2 - «Digital Computer Administrator» cuja função consiste preponderantemente em supervisionar e gerir as atividades do conjunto eletrônico.

3 - «Digital Computer Programming» cuja missão é precisamente a de «programar» as máquinas. 
4 - «Digital Computer Systems Operations», ou seja, o operador encarregado do funcionamento das máquinas.

5 - «Peripheral Computer Equipment Operation». A missão classificada sob esta rubrica consiste em assegurar o funcionamento de todo o equipamento periférico: perfuradoras, impressoras, etc...

Essas novas funções diferem radicalmente de tôdas as até agora conhecidas ou previstas. Por isso, impõe-se, forçosamente o trabalho de descobrir e executar novos métodos de seleção, preparo, formação e contrôle do pessoal convocado para desempenhá-las. O problema continua, por conseguinte, sendo objeto de continuas pesquisas.

\section{C) Adaptação da organização Administrativa aos conjuntos eletrônicos}

Cumpre assinalar, neste campo, que a automação provoca - como não poderia deixar de ser - uma reforma dos métodos de trabalho e das estruturas. As modificações nos métodos vinculados, por exemplo, aos quadros de direção, podem ser resumida em 3 principais: I - os quadros superiores deverão conhecer os rudimentos de funcionamento das instalações eletrônicas a fim de poder adaptar-lhes as suas técnicas de trabalho. Tais conhecimentos não bastam naturalmente para transformá-los em especialistas mas em pessoas que estejam ao par das possibilidades e dos limites da automação; II - uma adaptação será igualmente necessária para que os funcionários de nivel superior estejam em condições de saber se utilizar dos dados fornecidos pelo conjunto eletrônico, os quais se apresentam de maneira tôda especial; III - é preciso também que êsses funcionários se preparem para um contrôle racional e global dos dados fornecidos, assegurando-lhes uma continua revisão notadamente quando se trata de um trabalho estatistico. Os estatísticos trabalhando na administração devem verificar em que medida seus métodos de trabalho e suas técnicas podem se adaptar à automação.

Ao concluir a sua exposição, Mr. Hattery insiste a respeito da conveniência da necessidade e da urgência da automação no âmbito dos serviços públicos. «À Semelhança do ouro - afirma o técnico norte-americano «a automação deve ser apenas um instrumento a serviço do Homem e não o seu Senhor».

2. OS Debates À margem da exposição de Mr. Lowell Hattery

Pronunciamentos dos Delegados do Vietnam, França, Inglaterra, Índia, Bélgica, Egito, Holanda, Estados Unidos, Iugusláviă, Brasil e Itália.

Encerrada a exposição de Mr. Lowell Hattery teve início a discussão geral relativa aos problemas da automação no âmbito da administração pública. No decorrer dos debates falaram os Delegados dos diversos países convocados à Mesa Redonda de Liège, destacando-se as intervenções formuladas pelos representantes dos seguintes países: M. M. Lyonel Wurmser, Henry Puget, Jean Milhaud, da França; Sir John Simpson e Mr. G. H. S. Jordan, da Inglaterra; M. M. Roger Leblanc e P. A. Schillings, da Bélgica; Mr. Herbert Emmerich, dos Estados Unidos; M. Gerritvan Poelge e M. M. R. Starreveld, da 
Holanda; Mme. Seeta Parmanand e M. V. K. N. Menon, da Índia; M. Nikola Stjepanovic, da Iuguslávia; Dr. Luís Simões Lopes, do Brasil; Mr. Osman Khalil, do Egito; M. Cataldi, da Itália.

RESUMO GERAL DAS INTERVENÇÕES. SÍNTESE DA MESA REDONDA.

1. Um Delegado do Vietnam, cujo nome escapou ao presente resumo taquigráfico estima que, contràriamente à opinião dos que não estabelecem qualquer diferença entre mecanização e automação, é necessário fazer essa distinção: durante o seu funcionamento a automação pode se corrigir a si própria e tratar os dados sem intervenção humana. Considerada a automação nos diversos domínios da atividade industrial, verifica-se sua importância tôda especial para os países em fase de desenvolvimento que devem enfrentar uma dura concorrência estrangeira. No campo dos trabalhos de escritório - acentua o represntante do Vietman - são inúmeros os setores e tarefas susceptíveis de automação. A implantação de conjuntos eletrônicos nas administrações públicas exigirá uma alta capacidade de adaptação, porque a automação susceptivel - conforme o uso que dela se fizer - de ser ao mesmo tempo a melhor e a pior das coisas.

2. M. Lyonel Wurmser (França), Presidente da Sessão, adverte o orador e apela para os Senhores Delegados a fim de que limitem o objeto das discussões aos aspectos administrativos da automação, abstração feita de considerações sôbre a automação em geral. Mesmo no limite dos aspectos administrativos é preciso fazer uma escolha porquanto tais aspectos são variadissimos.

3. M. Henry Puger (França) - falando não como técnico, mas como um prático, de há longa data, e com a experiência que possui - deseja pôr em relêvo alguns perigos que a automação apresenta na administração público. Êstes perigos devem ser considerados antes mesmo da instalação dos conjuntos eletrônicos. São perigos de várias ordens: 1 - um risco do desperdício de dinheiro; 2 - um risco de má utilização dos efetivos, notadamente do pessoal tornado disponivel pela introdução da automação; 3 um risco de paralisia em conseqüência de interrupção no funcionamento dos conjuntos eletrônicos. por ausência do pessoal, pane ou sabotagem.

4. M. Lyonel Wurmser (França) - julga que as duas primeiras observações de M. H. PuGET são fundadas, mas, que tais riscos podem ser enfrentados por uma boa organização e um planejamento rigoroso. Reconhece, todavia, que o risco de paralisia consoante a definiu M. Henry Puget existe no que concerne a eventualidade de um ato de sabotagem. A correção mediante um trabalho paralelo ou um outro método qualquer de emergência, far-se-ia sempre ao preço de um custo ainda mais alto.

5. Sir John Simpson (Inglaterra) - insiste sôbre a necessidade de transformar a mentalidade tanto dos quadros dirigentes como dos executantes, a fim de prepará-los para a realização de um trabalho de acôrdo com métodos inteiramente diferentes do que êles conheceram durante uma atividade muitas vêzes longa. Na opinião de Sir J. Sımpson urge uma defesa contra a tendência em querer obter sempre mais dados estatísticos quando êstes deveriam, ao contrário, serem reduzidos ao mínimo necessário. 
6. Mme. Seeta Parmanand (Índia), falando como sindicalista, examina o problema sob o ângulo dos mercados de emprêgo e trabalho e, interroga se tais questões devem ser examinadas pelo I.I.A.S. (International Institute of Administrative Sciences) ou por outras organizações mais especializadas. Depois de ter estudado o problema sob o ângulo sociológico e econômico, ela pensa que, de qualquer forma, no domínio do estado, como do capital privado, o pessoal deveria ser consultado antes de qualquer decisão tomada no sentido de introduzir a automação.

7. Mr. G. H. S. Jordan (Inglaterra), partindo da experiência, dos ddaos e dos documentos de trabalho do I.I.A.S. constata que os principais benefícios da automação são adquiridos aonde anteriormente não havia uma mecanização muito avançada; verifica, em seguida, que a utilização de um mesmo equipamento para solução de problemas diferentes no seio do mesmo serviço ou entre diversos serviços dá origem a um importante problema de coordenação que anula, em parte, a economia que seria obtida mediante a aquisição de um equipamento importante no lugar de vários equipamentos médios. De uma maneira geral, observa-se que se a evolução administrativa atual tende para a descentralização, a automação, ao contrário, tende à criar as condições de uma nova centralização. E pergunta se as atividades tais como as desenvolvidas pelos serviços sociais, - não necessitarão sempre e cada vez mais de uma descentralização avançada. No tocante ao pessoal, Mr. Jordan M. HAtTery, manifesta suas dúvidas quanto aos fundamentos da posição assumida pela Civil Service Comission norte-americana; Mr. JoRDAN além disso acredita que a introdução da automação na administração britânica não será de natureza a criar, de imediato, problemas de pessoal. Os principais motivos em que se baseia Mr. Jordan para emitir estas opiniões são: - o fato de que há falta, no momento, de empregados de certos encargos; a perspectiva de um aumento continuo dos trabalhos de escritório, principalmente em matéria estatística. Êle assinala, além disso, que contràriamente ao método habitual de seleção baseada sobretudo em entrevistas, a seleção de pessoal destinado a se servir dos equipamentos eletrônicos e a se ocupar da programação faz-se atualmente, por meio de testes. Êstes, porém, ainda não tiveram tempo suficiente para demonstrar o seu mérito.

8. Mr. Roger Leblanc (Bélgica), tomando a palavra também como sindicalista, sublinha a importância da consulta sindical prévia à implantação da automação nos serviços públicos. Considerando que no setor privado, a automação, favorece e serve de base para tôda modificação importante de estrutura, Mr. Roger LEBLANC não vê motivo pelo qual não se faria o mesmo na administração pública. Poder-se-ia ùtilmente ampliar a participação sindical estendendo-a aos esforços tendentes a aumentar a produtividade nas administrações.

9. Mr. Osman Khalil (Egito), se esforça para reconduzir a discussão ao seu objeto - a automação na administração pública - e não em outros dominios. E sugere a consideração dos três pontos seguintes, relativos à incidência da automação sôbre a administração pròpriamente dita: 1) a automação provoca uma centralização contrária à tendência do século que é um século de descentralização; 2) as conseqüências financeiras da automação 
e sua incidência sôbre o Orçamento: isto é especialmente verdądeiro para os paises sub-desenvolvidos nos quais se deve estabelecer uma estrita e rigorosa hierarquia de prioridade na utilização dos fundos públicos; 3) a influência da automação sôbre a formação do pessoal. Poder-se-ia admitir uma formação diversa da formação em ciências administrativas e sociais?

10. Mr. Gerrit van Poelje (Holanda), partindo de sua experiência pessoal acha que não cabe mais perguntar se é, ou não, preciso, introduzir a automação nos serviços públicos. A automação é uma necessidade inevitável e far-se-á implantar, queiram ou não. Cumpre, portanto, examinar como introduzí-la com o mínimo de repercussões novas - tanto para a administração como para os homens que a servem.

11. Mr. Paul Schillings (Bélgica), dá início à $2^{\mathrm{a}}$ parte da Sessão de trabalho solicitando que os debates se concentrem sôbre as duas questões básicas por êle formuladas no sábado passado: $1^{\circ}$ - como o Instituto deve continuar no futuro o estudo da automação? Esta pergunta se refere tanto à atividade dos serviços do I.I.C.A. (Instituto Internacional de Ciências Administrativas) como à das Seções Nacionais, Comitês Permanentes e Reuniōes; $-2^{\circ}-$ quais os problemas que urge estudar quanto ao fundo, problemas gerais ou especificos?

Um Delegado Alemão, nessa oportunidade, intervem para observar que a diferenciação entre a mecanização e a automação é acessória. $O$ que interessa é saber quais são os serviços que ambas podem prestar a administração.

12. M. L. Wurmser (França), solicita que se proponham assuntos específicos para as próximas reuniões, em matéria de automação, e que se apresentem sugestões úteis ao prosseguimento dos trabalhos do Instituto.

13. M. Herbert Emmerich (Estados Unidos), esclarece que o I. I. A. S. deve absolutamente continuar a se ocupar da automação nos limites das repercussões desta nova técnica sôbre a administração pública e o ensino das ciências administrativas; as questões de ordem técnica poderiam ser debatidas em Comités mais restritos (podendo ser Sub-Grupos do C.A.P. - Comité de Práticas Administrativas) - compostos de especialistas. M. Herbert EmMerich examina, em seguida, mais particularmente, as sugestões que podem prender a atenção para um estudo geral, notadamente as repercusssões da automação sôbre o ensino e a formação.

14. O Presidente da Sessão, M. L. Wurmser (França) gostaria de ver discutida, fora das reuniões, a eventualidade de um intercâmbio de informações.

15. M. JoRDAN (Inglaterra) assevera que, em sua opinião, o estudo da automação nos seus aspectos técnicos não é da alçada do International Institute of Administrative Sciences; todos os interessados na automação se dirigirão antes aos «experts» e o I. I. A. S., corre o risco de receber informações de segunda mão. Por outro lado, os trabalhos do Instituto Internacional podem instituir uma duplicidade dado que a UNESCO já se ocupa da questão. Para fazer um trabalho útil seria preciso que o I. I. A. S. se limitasse ao estudos dos problemas levantados pelo Delegado da República Árabe Unida em sua intervenção. 
Respondendo, então, a um pedido de indicações complementares de Mr. Schillings, Mr. Jordan insiste acêrca da oportunidade para o I.I.A.S. de ser um centro de intercâmbio de informações de natureza técnica.

16. Mr. Jean Milhaud (França), sugere que o I. I. A. S. continue, como no passado, a ser um centro de ligação entre as Seções Nacionais, e a aprofundar o estudo sôbre os casos de automação já realizados, organizando Seminários de formação com participação restrita, como já se fez na França, no quadro das atividades da C. E. G. O. S.

17. M. Nikola Stjepanovic (Iuguslávia), de sua parte, julga preferivel que o I. I. A. S. não continue mais a manter a automação no programa de suas reuniões, mas que, de maneira contínua, se ocupe da difusão de informações nesse campo através da Revista, publicações de artigos, "comptes rendus», ou qualquer meio adequado) bem como deverá o I. I. A. S. completar sua documentação sôbre a matéria. O I. I. A. S. tornarse-ia, assim, uma espécie de «clearing house» em matéria de automação, conforme parece ser o desejo da maioria dos Delegados.

18. Mr. V. K. N. Menon (Índia), emite uma opinião análoga, acentuando que a estudo em reunião é inútil para os especialistas no plano técnico, e incompreensivel para os que não são iniciados nos mistérios ou segredos da automação. É preciso pois permanecer adstrito aos aspectos e problemas administrativos. Todavia, está de acôrdo com a opinião de Mr. StJepanovic de ver o I.I.A.S. se transformar em uma «Clearing House» em matéria de automação.

19. M. R. Starreveld (Holanda), propõe, em nome da Delegação de seu pais, que diversos pontos sejam objeto de discussão no tocante à possibilidade e aos métodos de intercâmbio internacional relativamente às técnicas de automação: - $1-$ A coleta de informações deve ser feita esporàdicamente por meio de questionários, ou de maneira continua, mediante a remessa de informações ao I. I. A. S. pelas Seções Nacionais? Em resposta a essa pergunta, sugere M. STARREveld que os centros nacionais adequadamente informados dos projetos em andamento, nos respectivos países, possam informar satisfatòriamente o I. I. A. S. Este último informaria os ditos Centros por meio de circulares periódicas, dos projetos dos outros países, classificados por assunto, por tipo de problema e por modêlo de instalação utilizada. Os Centros poderiam solicitar, inclusive diretamente aos diversos países, os detalhes necessários; - 2 - Será desejável a contínua publicação dos progressos realizados nos diversos países? Em caso afirmativo, pela Revista, ou por informação direta dos Centros ? Sôbre êste ponto o orador gostaria que «Revista» mencionasse os estudos de casos de interêsse geral. E que sòmente se remetessem para os Centros listas exaustivas de projetos a fim de evitar as atividades indesejáveis de certos vendedores; - 3-Para quais projetos, é útil e possivel: a) estabelecer um sistema de intercambio de informações antes de abril de 1959, seja por via oral, ou por carta; b) resumir esta experiência e suas conclusões em um Relatório especial a apresentar ao Congresso de 1959?

A estas perguntas responde o orador da seguinte forma: a) uma aproximação geral do problema é possivel: 1 - entre representantes dos governos centrais agrupados em comissões; 2 - no seio de um mesmo minis- 
tério ou serviço; 3 - por todos os órgãos administrativos (locais, provinciais, etc.) e por informações dadas pelos comités centrais; b) convém não permutar as experiências senão para um número muito limitado de assuntos (por exemplo, os salários, o impôsto sôbre a renda, etc.), escolhidos entre os indicados pelos centros nacionais. Os membros dos Grupos de Trabalho devem ser técnicos, tanto em automação, como nas matérias tratadas para os serviços em causa.

4 - No tocante aos problemas de pessoal que assuntos devem ser escolhidos como objeto de estudo para o Congresso de 1959? Aqui o orador sugere: 1 - definir as categorias de trabalhos necessários na administração automatizada, os critérios de seleção e a formação necessária; 2 - o intercâmbio dos programas de formação; 3 - a informação do pessoal e os meios de evitar tôda agitação durante as fases preparatórias de um projeto.

5 - Estudos do mesmo gênero são conduzidos ou estão em andamento em outras organizações internacionais, tais como a UNESCO, a UEO, a OECE ou as entidades postais e ferroviárias? O orador aconselha neste ponto aproveitar tudo o que existe e não esperar que uma base de trabalho seja encontrada para permitir a cooperação.

20. Dr. Luis Simões Lopes (Brasil), considera que o I. I. A. S. deve continuar a se ocupar da automação. Insiste, porém, sôbre o fato de que o Instituto deveria concentrar os seus esforços: 1 - nos aspectos financeiros e orçamentários; 2 - nos problemas de formação; e 3 - nas questões relativas à adaptação e às mudanças do pessoal.

21. M. CATAldi (Itália), propõe: a) que o estudo da automação seja precedido de um estudo mais avançado da mecanização já introduzida ou a introduzir na atividade administrativo; b) que o I. I. A. S. exprima aos diversos governos o desejo de que os mesmos promovam os estudos de adaptação da legislação atualmente em vigor tendo em vista a introdução da automação.

22. M. Lyonel WuRMSER (França), encerrando a discussão geral procurou traçar um resumo e classificar as opiniões e sugestões emitidas durante os trabalhos. Finalmente, propôs que o I. I. A. S. concentrasse os seus esforços sôbre as 2 questões seguintes: a) os meios de ação a empregar a fim de que o I. I. A. S. seja realmente uma «Clearing House» em matéria de automação; b) os questionários ou os contactos diretos a providenciar no sentido de preparar um estudo acêrca dos problemas de pessoal em função da automação. 